\title{
A reforma tributária do governo Lula: continuísmo e injustiça fiscal
}

\author{
Alexandrine Brami-Celentano \\ Institut d'Études Politiques de Paris (Sciences Po)
}

\author{
Carlos Eduardo Carvalho ${ }^{1}$ \\ Pontifícia Universidade Católica de São Paulo (PUCSP)
}

\begin{abstract}
A reforma tributária do governo Lula: continuísmo e injustiça fiscal
Resumo: A reforma tributária proposta pelo governo Lula em 2003, aprovada rapidamente pelo Congresso, manteve-se nos limites das propostas do PSDB e do governo FHC, inspiradas pela ideologia neoliberal. Os pequenos avanços para reduzir a regressividade, como a desoneração de produtos da cesta básica de consumo, não revertem o papel da estrutura tributária na concentração da renda, com o predomínio dos impostos indiretos e de seus efeitos regressivos. A tributação tem merecido pouco destaque no amplo debate sobre as políticas sociais no Brasil, concentrado na repartição da despesa pública e na eficácia dos gastos, sem a devida atenção ao papel da estrutura tributária na concentração da renda e da riqueza no país. O artigo apresenta o perfil regressivo da estrutura tributária brasileira, preservado pela reforma de 2003, e discute a agenda neoliberal que orientou as iniciativas do governo Lula nessa área.

Palavras-chave: reforma tributária de 2003, governo Lula, estrutura tributária brasileira.
\end{abstract}

\section{Tax Reform in the Lula Government: Continuity and Fiscal Injustice}

Abstract: The tax reform proposed by the Lula government in 2003, quickly approved by Congress, remained at the limits of the proposals of the previous government of President Fernando Henrique Cardoso and his Social Democratic party (PSDB), inspired by neoliberal ideology. The small advances in reducing regressivity, such as exemptions for basic consumer products, have not altered the role of the tax structure in the concentration of wealth, with a predominance of indirect taxes and their regressive effects. Taxation has deserved little attention in the broad debate about social policies in Brazil, which concentrates on the allocation of public expenses and the efficiency of spending, without proper attention to the role of the tax structure in the concentration of income and wealth in the country. The article presents the regressive profile of the Brazilian tax structure, preserved by the reform of 2003 and discusses the neoliberal agenda that guides the initiatives of the Lula government in this field.

Key words: tax reform of 2003, Lula government, Brazilian tax estructure. 


\section{Introdução}

A tributação tem recebido pouco destaque no amplo debate sobre as políticas sociais no Brasil, concentrado quase sempre na repartição da despesa pública e na eficácia dos gastos para melhorar a distribuição de renda e para promover a integração de todos nos benefícios do desenvolvimento econômico e da acumulação de riqueza pela sociedade.

O ocultamento do forte desequilíbrio na distribuição da carga tributária é um triunfo importante da agenda neoliberal, pela qual se orientou o governo de Fernando Henrique Cardoso (FHC). Esta agenda defende que os objetivos sociais da política fiscal sejam buscados na administração da despesa pública e que a tributação seja neutra, abandonando-se o princípio da progressividade, segundo o qual deve ser exigida maior contribuição de quem tem maior renda e maior riqueza. A adesão do governo Lula a esta orientação se definiu na proposta de reforma tributária encaminhada ao Congresso nos seus primeiros meses, aprovada de imediato.

Este artigo discute a reforma tributária do governo Lula em 2003 e critica o abandono dos objetivos de distribuição de renda e de progressividade que deveriam ter orientado esta e outras iniciativas, se Lula e o PT fossem fiéis ao seu programa e aos preceitos da Constituição de 1988. A proposta se concentrou no aumento da receita e em incentivos à eficiência das empresas, além de ajustes na repartição de receitas entre a União e os estados e municípios. Os pequenos avanços distributivos na legislação tributária, como a desoneração de produtos que compõem a cesta básica de consumo, não revertem o papel da estrutura tributária na concentração da renda e se tornam ainda menos relevantes diante dos elevados valores dos juros pagos pela dívida pública.

Além desta introdução, a primeira parte do artigo discute a agenda neoliberal, em que a reforma de 2003 se enquadra, a segunda parte apresenta um quadro resumido da estrutura tributária brasileira e de seu perfil regressivo e a terceira parte discute a reforma promovida pelo governo Lula, seguindo-se uma seção com algumas notas finais.

\section{Neutralidade tributária: a agenda neoliberal}

Formou-se nas últimas décadas uma agenda neoliberal para reformas tributárias nos países em desenvolvimento, disseminada nas recomendações do Consenso de Washington e das agências multilaterais, em especial o Fundo Monetário Internacional e o Banco Mundial (WILLIAMSON, 1990a, 1990b; WORLD BANK, 1989, 1992). A ideologia neoliberal é maleável o suficiente para ser adaptada às peculiaridades de cada país da periferia, mas está sempre voltada para dar espaço preponderante ao mercado e para reduzir o papel do Estado (BIRD, 1992a, 1992b; PRZEWORSKI, 1991):

\begin{abstract}
O neoliberalismo é um conjunto de idéias e valores bem mais amplo que as políticas econômicas que nele se referenciam e não apresenta um conjunto rígido e bem definido de políticas a serem aplicadas. Nos governos ditos neoliberais verifica-se grande variedade de políticas econômicas específicas, inclusive coexistindo no mesmo período. [...] Quando analisado pela ótica das políticas econômicas, o neoliberalismo se revela mais um paradigma que um receituário detalhado, mais um conjunto de valores gerais para orientar as políticas econômicas que um conjunto articulado de políticas específicas. É um paradigma forte o bastante para estabelecer limites rígidos para as orientações básicas das políticas a serem feitas, para estabelecer um campo de idéias difícil de ser rompido e contestado, mas é também um paradigma elástico e amplo o bastante para abrigar políticas específicas muito variadas e mesmo díspares entre si (CARVALHO, 2004, p. 132-133).
\end{abstract}

A neutralidade da estrutura tributária foi defendida tradicionalmente sob o argumento de que os impostos não devem provocar distorções nos preços e nas decisões econômicas. Esta tese, de inspiração liberal, foi substituída pelo reconhecimento de que a cobrança de impostos é um dos principais instrumentos para a correção dos desequilíbrios de renda e riqueza gerados pela economia de mercado. Estabeleceu-se assim a preferência pela cobrança dos impostos diretos, que incidem diretamente sobre a renda dos indivíduos e empresas e sobre a riqueza acumulada. O imposto de renda (IR), o mais importante dentre eles, estabelece alíquotas diferenciadas por faixa de renda e isenta, em geral, a maioria da população. Os impostos indiretos, ao contrário, afetam a todos igualmente, pois incidem sobre fatos econômicos gerais. O mais importante dentre eles é o imposto sobre as vendas, em geral na forma de imposto sobre o valor agregado. No Brasil, o imposto mais importante é deste tipo, o Imposto sobre Circulação de Mercadorias e Serviços (ICMS), ao lado do Imposto sobre a Produção Industrial (IPI) e do Imposto sobre Serviços (ISS).

A experiência internacional mostra uma multiplicidade de impostos, o que compensa os inconvenientes de cada imposto isoladamente, atingindo diferentes fatos econômicos (renda, consumo, patrimônio, etc.) que representam as possibilidades contributivas dos indivíduos. Ciente da predominância dos impostos diretos nos países centrais, a ideologia neoliberal recomenda aos países periféricos a 'neutralidade' da estrutura tributária e o deslocamento das preocupações com a distribuição de renda para o gasto público. A 
estrutura tributária não deveria ser direcionada para as rendas mais altas, sob a alegação de que é muito custoso fazê-lo e os resultados são fracos. O argumento é de que, nos países periféricos, a evasão fiscal é endêmica e difícil de controlar, além dos efeitos da chamada elisão fiscal, o aproveitamento de falhas na legislação por parte dos contribuintes de altas rendas para reduzir os impostos a pagar, prática conhecida no Brasil como 'planejamento tributário'.

A 'neutralidade' da tributação, contudo, é negada no controle dos gastos. Aplica-se aqui a ideologia da 'responsabilidade fiscal' sobre os gastos sociais, mas não sobre as despesas com os juros sobre a dívida pública. Apesar de representarem parcela substancial do gasto público, os juros não são tratados como despesa pública passível de disciplinamento, e sim como necessidade indiscutível, decorrência 'natural' das opções de política monetária do Banco Central, para o qual não deve haver limites legais, ao contrário dos constrangimentos impostos aos gastos sociais.

As reformas tributárias tiveram papel relevante na América Latina, para a estabilização da moeda, a liberalização da economia e a reconstrução do núcleo do poder estatal. Mahon (2004) destaca o desenho muito similar das reformas tributárias em 15 países da região, de 1977 a 1995, com menor progressividade, menos isenções, ênfase na tributação sobre o valor agregado e fortalecimento da administração tributária. A análise mostra também o vínculo entre as reformas e as condições impostas pelo FMI nos programas de apoio financeiro. As reformas tributárias no continente seguiram duas orientações básicas (CARVALHO, 1997). A primeira delas é a redução do papel da tributação direta, sob a tese de que aperfeiçoar o IR é muito caro e difícil, pelos problemas de evasão e elisão, reforçados pela abertura financeira que permite a migração e o mascaramento da titularidade de recursos de alta liquidez. Não se discutem alternativas de reforço da fiscalização no IR, inclusive com a experiência dos países centrais, em que a cobrança rigorosa do IR é bastante enfatizada, nem se discute a cooperação internacional para combater a circulação de recursos com origem criminosa, como é o caso da evasão fiscal.

A segunda orientação é simplificar a tributação indireta, em especial o imposto sobre o valor agregado, reduzindo a diferenciação de alíquotas e as isenções ou favorecimentos, feitas com propósitos sociais ou de desenvolvimento. Defende-se que a simplicidade favorece o controle e a fiscalização, o que permite ampliar a base de incidência do imposto com custo menor que os possíveis benefícios gerados por isenções e alíquotas diferenciadas. As versões mais extremadas da agenda neoliberal chegam à proposta de simplificação extrema, o imposto único (flat tax) sobre transações financeiras. Sob o pretexto de maior simplicidade e neutralidade, o imposto único viabilizaria outro elemento relevante na agenda neoliberal: a eliminação, ou redução substancial, do caráter declaratório da riqueza acumulada, presente na cobrança do IR, impossível de ser feita sem que o cidadão apresente sua declaração de renda e de riqueza ao fisco.

Nos dois mandatos presidenciais do Partido da Social Democracia Brasileira (PSDB), as propostas de reforma tributária ficaram nos limites desta agenda neoliberal, com ênfase em três questões: gerar receita tributária para sustentar o programa de estabilização; resolver os conflitos entre Estados, de modo a permitir inclusive a desoneração das exportações; e tirar de cena o imposto de renda.

O projeto do governo Lula, de 2003, se inspirou fortemente nas propostas iniciais do governo FHC (PRESIDÊNCIA DA REPÚBLICA, 2006), severamente criticadas pela esquerda brasileira, inclusive pela bancada parlamentar do PT. Logo após sua posse, o governo Lula apresentou como suas as propostas do PSDB e conseguiu implementar boa parte delas.

\section{Tributação no Brasil: regressividade e con- centração de renda}

A estrutura tributária brasileira se caracteriza pelo predomínio da tributação indireta, ao lado de complexos mecanismos voltados para sustentar a composição federativa que articula os diferentes grupos e interesses dos Estados e regiões com a União.

A carga tributária total atingiu o recorde de $37,37 \%$ do PIB em 2005, mais de 12 pontos acima dos $25,72 \%$ do PIB em 1993, às vésperas do Plano Real (BRASIL, 2001, 2006). Trata-se de um verdadeiro paradoxo: a pressão fiscal vai além de um terço da renda nacional, proporção semelhante aos níveis da Europa Ocidental; mas o país, campeão de desigualdade, ocupa a $69^{a}$ posição no ranking do IDH das Nações Unidas, a despeito de contar com políticas sociais razoavelmente desenvolvidas (UNITED NATIONS..., 2006, p. 302).

Para o cálculo e a análise da carga tributária brasileira, são adotados diferentes conceitos e metodologias pelos órgãos oficiais (Ministério da Fazenda, Ministério do Planejamento e institutos nacionais de pesquisa) e por especialistas e acadêmicos. Adotamse aqui dados publicados pela Secretaria da Receita Federal (SRF), responsável pela arrecadação de tributos do governo federal. A SRF calcula o que denomina "carga tributária sob o conceito econômico": (i) inclui restituições e incentivos fiscais na arrecadação; (ii) realoca como receita federal o IR retido na fonte pelas administrações estaduais e municipais; e (iii) exclui as receitas relativas a refinanciamentos, parcelamentos, multas e juros relativos a tributos vencidos anteriormente à data de pagamento ${ }^{2}$. 
No Brasil, a metade da tributação provém do consumo, 48,49\% do total (BRASIL, 2006a), sem contar diversas taxas (para limpeza urbana e iluminação pública, por exemplo) criadas ad hoc pelos governos locais. Os impostos sobre valor agregado (ICMS, IPI) e faturamento (ISS) representam $26,76 \%$ do total das receitas, com mais $22,98 \%$ gerados por contribuições sociais (Contribuição para o Financiamento da Seguridade Social - COFINS, Programa de Integração Social - PIS, Contribuição Social sobre o Lucro Líquido - CSLL, Contribuição Provisória sobre Movimentação Financeira - CPMF) e econômicas (Contribuições de Intervenção no Domínio Econômico, dentro das quais a CIDE combustíveis) arrecadas pela $\mathrm{SRF}$.

No caso do ICMS (estadual), do ISS (municipal), e das contribuições sociais PIS e COFINS (federal), que somam mais de um terço do total das receitas $(37,71 \% \mathrm{em}$ 2005), a alíquota é fixada a partir do preço (da mercadoria, bem ou serviço) reajustado pelo montante de todos os tributos incidentes, inclusive o do próprio tributo, de modo que cada tributo incide sobre si próprio. Por exemplo, no cálculo do ICMS na conta de energia, $25 \%$ de $\mathrm{R} \$ 100$ vira $\mathrm{R} \$ 33$. Isso porque o valor do tributo é adicionado na base de cálculo para que seja calculado o valor a ser pago de ICMS. É a chamada cobrança 'por dentro' ou 'em cascata': os $25 \%$ são cobrados em cima de R\$ 125. Esta sistemática de cobrança eleva muito o preço de serviços essenciais (energia, água, telefonia fixa) e torna a tributação brasileira pouco transparente, pois o contribuinte não consegue saber quanto paga pela mercadoria ou serviço e nem quanto de tributo.

Para os mais pobres (o primeiro quintil de renda per capita), a tributação indireta equivale a $74 \%$ do total de transferências monetárias que recebem do governo (REZENDE; CUNHA, 2002, p. 106-110). Esta relação é importante porque, na lógica mantida pelo governo Lula, a progressividade do sistema tributário deveria ser assegurada pelos programas de transferência de renda, os quais são financiados basicamente pela tributação indireta que afeta os mais pobres.

O peso dos tributos indiretos contrasta com o papel mais modesto do imposto de renda, que redistribui a renda por seu caráter progressivo, com alíquotas maiores para rendas maiores. Em 2005, o IR representava $18,27 \%$ das receitas fiscais e sua participa- ção no PIB, 6,82\%, estava muito abaixo da dos países da Organização para Cooperação e Desenvolvimento Econômico (OCDE): 9,54\% na Espanha, 10,96 $\%$ na Alemanha, $13,44 \%$ no Reino Unido, $15,86 \%$ no Canadá (AFONSO; MEIRELLES, 2006, p. 37).

O IR é arrecadado sob três formas. O IR retido na fonte (IRRF), que representa $3,92 \%$ do PIB e fornece $57 \%$ do total do IR, incide principalmente sobre salários pagos a pessoas físicas; o IR sobre empresas (IRPJ) arrecada $2,55 \%$ do PIB e $37 \%$ do IR total; e o IR sobre pessoas físicas (IFPF) apurado nas declarações anuais responde por $0,33 \%$ do PIB e $5,2 \%$ do IR total.

O peso elevado do IRRF sobre os salários decorre em parte da correção parcial das faixas de incidência pela inflação, o que eleva o IR devido pelos assalariados que conseguem reajustes salariais

(UNAFISCO SINDICAL, 2006).

Por outro lado, as alíquotas foram reduzidas a três em $1994(0 \%, 15 \%$ e $25 \%$, esta elevada para $27,5 \%$ em 1996), o que aliviou a pressão tributária sobre as rendas mais altas - a alíquota máxima de $27,5 \%$ é 14 pontos menor que nos EUA e $13 \%$ menor que no Reino Unido (OECD, 2006). As altas rendas são muito favorecidas por várias formas de reduzir o pagamento de IR, muitas delas legais. Apesar da sofisticada estrutura de informações e controle, o acúmulo de brechas na legislação permite a estas pessoas a redução do IR devido, inclusive pela dedução de despesas com educação, saúde e previdência privada.

As rendas mais altas são ainda mais protegidas porque a tributação sobre o patrimônio é pequena, apenas 3\% das receitas públicas, e muito desproporcional à sua distribuição - a renda de 5 mil famílias equivale a 45\% do PIB (POCHMANN et al., 2004). A tributação sobre o patrimônio atinge principalmente imóveis (Imposto sobre Propriedade Predial e Territorial Urbana - IPTU, de competência municipal) e veículos (Imposto sobre Propriedade de Veículos Automotores - IPVA, de competência estadual). A tributação sobre heranças e doações, reduzida nos países desenvolvidos $(0,21 \%$ do PIB, em média), é insignificante no Brasil (o Imposto sobre a Transmissão Causa Mortis e Doações - ITCD estadual mantém-se estável, em torno de $0,04 \%$ do PIB) (ANDRADE et al., 2000). O imposto sobre as grandes fortunas, incluído na Cons- 
tituição de 1988, ainda depende da aprovação de lei complementar e ficou fora de todas as propostas de reforma tributária no Congresso.

Por todos estes fatores, a tributação direta atinge principalmente as classes médias, devido a que seu nível de renda se enquadra nas faixas de tributação do imposto de renda na fonte, em especial nos segmentos assalariados de renda média (as classes B e C na classificação do IBGE, com renda média mensal de 5 a 20 salários mínimos).

O fator tributário contribui para explicar o significativo deslocamento das populações com padrão de vida médio e baixo para os níveis de pobreza nas últimas décadas, processo revertido apenas parcialmente nos últimos anos, com a maior estabilidade econômica e os programas de transferência de renda. Ao longo dos anos 1990, houve, entre profissionais, massa trabalhadora agrícola, massa trabalhadora não agrícola e sem ocupação com renda, um generalizado processo de desclassificação social, com aumento na participação dos estratos de renda mais baixa. Estes dois fenômenos - rebaixamento social da classe média e da massa de trabalhadores, e aumento da miséria metropolitana - caracterizam uma tendência paradoxal de polarização social 'para baixo', em contraposição às tendências opostas ressaltadas pela literatura internacional (GORI MAIA; SIQUEIRA; QUADROS, 2006, p. 23).

A tributação sobre os salários, em especial as diversas contribuições a serem pagas pelas empresas, agrava a tendência à informalização do mercado de trabalho. Apesar dos avanços obtidos nos últimos dois anos, o trabalho informal continua na faixa de $50 \%$ da força de trabalho ocupada, ao lado do elevado desemprego. As contribuições sociais que financiam a Seguridade Social (contribuições previdenciárias arrecadadas e geridas pelo Instituto Nacional de Seguridade Social - INSS, mais contribuições sociais vinculadas a programas sociais - COFINS, PIS/ PASEP, CPMF, CSLL) representam $38,80 \%$ das receitas fiscais e atingem a renda dos assalariados, na forma de descontos na fonte. Os encargos sobre os salários (previdência e direitos sociais - férias, décimo terceiro salário, descanso semanal) desencorajam a contratação formal de trabalhadores. Pesquisa recente da OCDE (2005) argumenta que as dificuldades de ampliação do emprego formal no Brasil são mais tributárias que jurídicas.

Para micro e pequenas empresas, formadas em geral por empreendedores independentes ou por familiares, foi criado o Sistema Integrado de Pagamento de Impostos e Contribuições (Lei n. 9.317, de 05/12/ 1996), o Simples, que permite o pagamento unificado do IRPF, PIS, COFINS, CSLL, INSS Patronal e IPI. Para as pequenas e médias empresas, que não consigam se enquadrar nas condições do Simples, parece mais atraente não registrar seus empregados e correr os riscos de multas ou processo trabalhista.

Para muitos trabalhadores, a precariedade do emprego indica que dificilmente poderão manter empregos formais durante os anos requeridos para a aposentadoria, o que reforça a opção de aceitar empregos não formalizados. Esta situação prejudica a arrecadação do INSS, reduz suas possibilidades de autofinanciamento e aumenta a pressão contra qualquer tentativa de reduzir as contribuições previdenciárias sobre trabalhadores e empresas.

Outra questão de grande relevo no caso brasileiro é o papel das desigualdades regionais como fator de agravamento das desigualdades sociais. O objetivo de integração nacional, sob o ângulo da inclusão social e da solidariedade regional, está no núcleo da Constituição de 1988 (BRASIL, 1999, tít. 1, art. $3^{\circ}$ ), no mesmo nível fundamental que a separação dos Três Poderes e a organização federativa, como elemento básico do federalismo fiscal.

A Constituição de 1988 previu dois sistemas de repartição federativa das receitas, repasse automático de impostos e transferências indiretas. Ao contrário de outras federações, estas últimas se fazem da instância de nível superior para as de nível inferior, da União para estados e municípios (cerca de 4,5\% do PIB) e dos estados para os municípios (cerca de 2,6\% do PIB). As receitas fiscais federais destinadas à redistribuição indireta são repartidas em cinco fundos de participação principais, com base em níveis de renda e na população. A União chega a transferir $47 \%$ da arrecadação do IR e 57\% do IPI. Toda mudança nestes critérios de repartição deve ser feita por emendas constitucionais. O conjunto de transferências constitucionais complementa as chamadas 'transferências legais', regulamentadas em leis específicas, incluindo transferências automáticas para estados e municípios (na área de educação, como alimentação escolar e o Programa Dinheiro Direto na Escola) e as transferências no âmbito da saúde e assistência social.

\section{A reforma tributária do primeiro mandato de Lula}

O programa de governo do candidato Lula incluía uma reforma tributária, sem detalhar o que seria feito. Pouco mais de três meses depois da posse, em abril de 2003, o novo governo enviou ao Congresso uma Proposta de Emenda Constitucional (PEC), voltada para reformar o sistema tributário e os critérios de repartição federativa das receitas. Depois de tramitação muito rápida, a Emenda Constitucional 42 foi promulgada em 19 de dezembro.

A proposta foi elaborada no Ministério da Fazenda, levada ao presidente da República em fevereiro e logo submetida, para debate sumário, ao Conselho de Desenvolvimento Econômico e Social, órgão consulti- 
vo da Presidência da República, formado por representantes da sociedade civil escolhidos pelo governo, cujo peso político declinou ao longo do governo Lula.

Na apresentação da proposta, o governo indicava o objetivo geral de "desenvolvimento integral e duradouro do país", com "justiça fiscal”, e assegurava que a reforma seria "neutra", no sentido de que não aumentaria a carga tributária (PALOCCI FILHO; DIRCEU, 2003). O termo tinha uso pouco rigoroso. Um dos princípios das finanças públicas propugna a "neutralidade tributária", mas no sentido de que a incidência fiscal não deve afetar, na medida do possível, as escolhas do cidadão quanto ao trabalho ou lazer, poupar ou gastar, nem quanto à forma de sua atividade econômica. Na proposta de 2003 , a menção à neutralidade fiscal poderia ser entendida como tentativa de ganhar credibilidade junto aos organismos multilaterais e ao setor produtivo, sem explicitar o objetivo maior, que era de fato viabilizar a qualquer custo, inclusive tributário, os superávits primários requeridos para reverter a tendência de crescimento da dívida pública.

Com 91 dos 512 deputados federais e 14 dos 81 senadores, o PT era numericamente fraco para obter a maioria (de 3/5) requerida para emendar a Constituição, mesmo considerando a base aliada, com a qual somava 254 deputados e 31 senadores. A tarefa de atrair muitos parlamentares dos partidos de oposição ficou com o então chefe da Casa Civil, José Dirceu. O governo procurou também obter apoio de governadores, pela sua influência sobre os parlamentares de seu estado (ABRUCIO, 2002). Em um lance político de grande repercussão, Lula convidou os governadores ao Palácio do Planalto no final de fevereiro de 2003, para pedir apoio e discutir o projeto de reforma. Depois de semanas de negociações, assinou com os governadores a Carta de Brasília, que expressa, de forma bastante precisa, o entendimento entre o governo federal e os estados em torno da reforma tributária. Em 30 de abril, em outro gesto de impacto, destinado a enfatizar a importância conferida à reforma, o presidente Lula compareceu ao Congresso Nacional para entregar a Proposta de Emenda Constitucional (PEC) n. 41, "destinada a alterar o Sistema Tributário Nacional e dar outras providências" (BRASIL, 2006b)

A maior parte das medidas contidas na PEC se referia ao capítulo $1^{\circ}$ do Título VI da Constituição de 1988, dedicado ao Sistema Tributário Nacional, com 18 artigos e bastante detalhado. A PEC n. 41 propunha mudanças substanciais para uniformizar a legislação do ICMS, reduzindo o número de alíquotas incidentes para cinco, no máximo (as legislações estaduais estabelecem alíquotas diferenciadas por produtos), cabendo ao Senado definir as cinco categorias de produtos correspondentes às taxas diferenciadas, com o consentimento de $3 / 5$ do Conselho Naci- onal de Política Fazendária (CONFAZ), que congrega todos os secretários da Fazenda estaduais. Propunha, também, proibir a edição de normas específicas pelos estados para conceder vantagens a empresas e eliminar o fim do regime misto (origem/destino) de cobrança do tributo.

A PEC previa também que fosse incorporada à Constituição a Lei Complementar 87, a chamada Lei Kandir, de 1996, que suprimiu a incidência do ICMS na aquisição de bens para integração do ativo permanente e sobre as exportações de produtos primários e semi-elaborados, e garantiu compensação aos estados exportadores destes produtos. O governo federal se comprometeu a redistribuir mais $2 \%$ do IR e do IPI para os estados e municípios, com um novo fundo destinado a financiar projetos de desenvolvimento nas regiões mais pobres. Esta mudança na repartição dos recursos arrecadados pode ser considerada um dos traços da reforma destinados a reduzir a concentração de renda, em nível regional.

Foram anunciadas também outras medidas ditas progressistas, como a intensificação do combate à evasão fiscal e à sonegação, além do uso mais intensivo de alguns impostos diretos sobre o patrimônio com natureza progressiva: sobre a propriedade rural, o ITR federal; sobre a herança e doações, o ITCD estadual; sobre a transmissão de bens imóveis, o ITBI municipal.

No ICMS, o projeto previa que os produtos com alíquota mais baixa deveriam ser os produtos de consumo popular, como medicamentos, alimentação. A intenção inicial do Executivo era que estes produtos tivessem alíquota apenas simbólica, mas unificada em todo o país. O projeto previa também a ampliação e aprofundamento do Simples.

A PEC prorrogou até 2007 o percentual de $20 \%$ de Desvinculação de Receitas da União, a DRU, mecanismo criado na preparação do Plano Real, em 1993 e prorrogado deste então. Em relação ao capítulo da Constituição dedicado à Seguridade Social, que contém as disposições sobre as contribuições sociais, a PEC propunha eliminar a incidência cumulativa da COFINS, que passaria a ser não-cumulativa, com alíquota mais alta, definida pela lei. O projeto retomou o mecanismo adotado em dezembro de 2002, que havia abolido a incidência cumulativa do PIS. A PEC previa ainda a prorrogação da CPMF, com alíquota fixa de $0,38 \%$. A CPMF foi criada em 1996, com caráter provisório, substituindo o Imposto Provisório sobre Movimentação Financeira, IPMF, criado em 13 de julho de 1993. A alíquota da CPMF, originalmente de $0,20 \%$, foi elevada para $0,38 \%$. Inicialmente os recursos obtidos a partir da taxação sobre a movimentação financeira seriam destinados às políticas de saúde, mas hoje vão também para o Fundo de Combate à Pobreza. Em 2006, o governo arrecadará, com a CPMF, R\$ 32 bilhões. 
Excluída a questão central da reforma do ICMS, o projeto de reforma tributária aparece como uma lista de medidas sem unidade e muito aquém da pauta de questões colocada pelo sistema tributário brasileiro, como a redistribuição da renda e da riqueza, o incentivo ao desenvolvimento econômico, o combate ao trabalho informal. As medidas de progressividade nos impostos sobre o patrimônio não seriam relevantes para mudar o quadro de regressividade, na medida em que o imposto sobre a propriedade rural (ITR), o imposto sobre heranças e doações (ITCD) e sobre a transmissão de patrimônio (ITBI) não representam mais que $0,14 \%$ do PIB.

A criação de tratamento diferenciado para produtos de primeira necessidade e trabalhadores pouco qualificados, e a extensão do sistema simplificado de declaração e recolhimento de tributos para certas categorias profissionais (microempreendedores,) revelam-se medidas compensatórias, tentativas de agradar os simpatizantes do PT. Segue a mesma lógica a confusão deliberada feita pelo governo entre os princípios de justiça social (ação redistributiva do sistema de tributos) e a noção liberal de 'justiça fiscal' (tratar com igualdade os contribuintes, sem questionar as desigualdades entre eles e, menos ainda, a necessidade de reduzi-las).

Ao conceito de justiça, muitos sociólogos e filósofos, como Rawls (1971, 2003), preferem o conceito de eqüidade, definida como o equilíbrio dado à aplicação estrita e mecânica da justiça, para contrabalançar a igualdade estritamente concebida. A teoria econômica e os especialistas em fiscalidade, por seu lado, utilizam alternativamente os conceitos de justiça fiscal e de eqüidade fiscal, entendidos como sinônimos. Qualquer que seja a definição aceita, os conceitos de justiça e de eqüidade estão no centro de grandes divergências.

Para uns, a eqüidade implica a contribuição igual de todos para financiar o gasto público, sem outros questionamentos. Para outros, a eqüidade é sinônimo de distribuição eqüitativa de recursos. A redistribuição é situada dentro do princípio de compensação das desigualdades geradas pelos mercados. Nesta perspectiva, o poder público tem que corrigir as desigualdades geradas pela economia de mercado, por meio da imposição fiscal que constitui um instrumento para financiar o gasto público e para promover a justiça social.

A tramitação da reforma foi dividida em três fases. A primeira, 'de urgência', continha, entre outras, medidas consideradas essenciais para garantir os níveis de receita em 2004, para a União e para os estados: prorrogação da CPMF e da desvinculação de $20 \%$ das receitas da União (DRU), transferência para estados e municípios de $25 \%$ das receitas da Contribuição de Intervenção do Domínio Econômico (CIDE) e de R $\$ 6$ bilhões do FPEx, o Fundo Constitucional de Compensação pela Exportação de Produtos Industrializados alimentado por $10 \%$ do IPI. Para terem efeito em 2004, teriam que ser aprovadas até 31/12/2003. A segunda fase, 'transitória', unificava a legislação do ICMS, com redução das alíquotas (de 44 para 5) e mudança do regime de cobrança (para a origem ou para o destino), para reduzir a concorrência fiscal entre os estados, medidas para vigorar em 2005. Por fim, a terceira fase, 'estruturante', previa a substituição dos três impostos sobre a produção (ICMS, IPI, ISS) em um Imposto sobre Valor Agregado (IVA), incidente sobre as mercadorias no destino, previsto para 2007.

O escalonamento da reforma permitiu ao governo adiar o debate das questões centrais - a reforma do ICMS e do federalismo fiscal - e acelerar a votação pelo Congresso das medidas que lhe interessavam. Em 19/12/2003, seis meses depois de entregue ao Congresso pelo presidente da República, a Emenda Constitucional n. 42 (BRASIL, 2006c) foi aprovada nas duas Casas por ampla maioria. O Senado Federal aprovou a PEC por 64 votos a favor e 4 contra no primeiro turno, e por 64 votos a favor e 5 contra no segundo turno. A Câmara aprovou a PEC por 378 votos a favor e 53 contra no primeiro turno $(88 \%)$, e por 346 votos a favor e 92 contra no segundo turno (79\%). As exportações de mercadorias e serviços ficaram isentas de ICMS (art.155, $2^{\circ}, \mathrm{X}$ ), o que tornou constitucional o princípio de não exportação da carga tributária nacional.

Além de prorrogar a DRU até 2007 e manter a CPMF de 0,38\%, a Emenda transferiu 25\% da CIDE para os estados $(18,75 \%)$ e municípios $(6,25 \%)$ a partir de 2004. O ITR passou a ser imposto progressivo e a arrecadação e a administração podem ser transferidas para municípios que o desejarem, mantida a competência da União para instituí-lo (art.153, $4^{\circ}$, III). Esta mudança foi justificada pela otimização do recolhimento pelos governos locais, mais próximos dos contribuintes, e pelo aprofundamento da descentralização tributária (LUGONES, 2004).

As alíquotas mínimas de IPVA passaram a ser fixadas pelo Senado $\left(\operatorname{art} .155,6^{\circ}\right.$ ), para harmonizar o 
imposto e evitar a guerra fiscal neste terreno, o que restringiu a autonomia dos estados sobre um tributo de sua competência. Por fim, para as micro e pequenas empresas, ficou definida a possibilidade de criação, por lei complementar, de um regime especial unificado de tributação que implicará o recolhimento mensal, mediante documento único de arrecadação, dos tributos dos três níveis de governo (art.146, III, d). 'Super Simples' ou 'Simples Nacional', como o regime é conhecido, unifica a tributação de empresas que tenham faturamento bruto anual que varie de $\mathrm{R} \$ 240$ mil a $\mathrm{R} \$$ 2,4 milhões. No total, devem ficar de fora do Super Simples cerca de 100 mil empresas.

Ao reunir em um único diploma legal as obrigações tributárias, trabalhistas e previdenciárias, além de acesso a crédito e mercados para as microempresas e empresas de pequeno porte, o Estatuto Nacional da Microempresa e da Empresa de Pequeno Porte (Lei Complementar n.123, de 14 de dezembro de 2006) acabou extrapolando seu objetivo inicial (simplificar o sistema Simples, mediante a instituição do Super Simples), o que gerou intensas negociações no Congresso (BRASIL, 2006d).

Em tese, a implementação de um tratamento fiscal diferenciado e simplificado de abrangência nacional para as pequenas e microempresas deveria reforçar a formalização de sua atividade, caracterizada por taxa elevada de informalidade e de evasão fiscal. Segundo dados do BNDES, 98\% das empresas do país são micro e pequenas empresas e respondem por cerca de $60 \%$ dos empregos gerados no país, participando com $43 \%$ da renda total dos setores industrial, comercial e de serviços.

\section{Notas finais}

A reforma tributária do governo Lula, apresentada e aprovada em 2003, não rompeu o caráter regressivo da estrutura impositiva e manteve os elementos essenciais da injustiça fiscal vigente no país. A Emenda Constitucional 43/03 limitou-se a mudanças localizadas na legislação, voltadas para aumentar a receita, como requerido pela política econômica, para estimular as exportações e para equacionar os conflitos entre os três níveis de poder da federação. Ficaram esquecidos ou foram tratados com muita timidez os objetivos de justiça fiscal/social, como o aumento da tributação sobre as rendas mais altas e sobre o patrimônio, a redução da tributação incidente sobre o consumo da maioria da população e a desoneração da folha de salários. A reforma rompeu com as propostas da esquerda e com as críticas que o próprio PT fez às medidas do governo FHC na área ao longo de seus dois mandatos.

$\mathrm{O}$ governo Lula aderiu inteiramente às teses neoliberais que orientaram as ações do PSDB e de FHC.
Para estas teses, a tributação deve ser neutra e os objetivos sociais devem ser deixados para a distribuição do gasto público. Trata-se de manter a estrutura tributária injusta, que coloca o peso maior da arrecadação sobre os mais pobres e sobre os assalariados, vítimas da tributação indireta, que atinge todos os produtos, e dos descontos do imposto de renda sobre os salários.

Uma avaliação favorável dirá que a reforma tributária de 2003 foi prova de um pragmatismo inevitável por parte de um governo que dispunha de margens de manobra muito estreitas na área fiscal, constrangido duplamente pela necessidade de gerar superávits primários e pelas dificuldades para atuar em área politicamente muito sensível. É certo que o enorme poder de pressão dos beneficiados pela concentração de renda e de riqueza dificulta qualquer avanço na área fiscal que atenda a objetivos sociais. Não é menos verdade, porém, que o presidente recém-eleito dispunha, em 2003, de grande legitimidade para empreender algumas iniciativas um pouco mais ousadas. O que ocorreu, ao contrário, foi a continuidade das propostas de reforma apresentadas e discutidas durante os dois mandatos do PSDB, do que resultou uma reforma em que os objetivos sociais ocuparam espaços muito modestos, como uma espécie de prêmio de consolação para os setores que viam na eleição de Lula e do PT a possibilidade de mudanças mais profundas no país.

\section{Referências}

ABRUCIO, F. L. Os barões da federação: os governadores e a redemocratização brasileira. São Paulo: Hucitec, 2002.

AFONSO, J. R.; MEIRELLES, B. B. Carga tributária global no Brasil, 2000/2005: cálculos revisitados? NEPP Caderno, n. 61, Universidade Estadual de Campinas, Núcleo de Estudos de Políticas Públicas, mar. 2006.

ANDRADE, M. I. de; ARAUJO, E. A.; FERREIRA, S. G.; VIVACQUA, F. Reforma tributária: o imposto (esquecido) sobre heranças, Informe SF, BNDES, Secretaria para Assuntos Fiscais n.11, mar. 2000. 6p.

BIRD, R. M. Tax Policy and Economic Development. Baltimore/London: The Johns Hopkins University Press, 1992a.

Tax Reform in Latin America: A Review of Some Recent Experiences, Latin American Research Review, 27, 1, p.7-36, 1992b.

BRASIL. Constituição da República Federativa do Brasil. Promulgada em 5 out. 1988. São Paulo: Atlas, 1999.

Ministério da Fazenda. Secretaria da Receita Federal. Coordenação-Geral de Estudos Econômico- 
Tributários. Carga Tributária no Brasil 2000, Texto para Discussão, n. 13, Brasília, jul. 2001, 21p.

. Ministério da Fazenda. Secretaria da Receita Federal. Coordenação-Geral da Política Tributaria. Carga Tributária no Brasil 2005, Estudos Tributários, n. 15, Brasília, ago. 2006a.

. Proposta de Emenda Constitucional n. 41, de 19 de dezembro de 2003. Disponível em <www.fazenda. gov.br>.Acesso em: out. 2006b.

Emenda Constitucional n. 42, de 19 de dezembro de 2003. Disponível em < www.planalto.gov.br/CCIVIL_03/ Constituicao/Emendas>. Acesso em: out. 2006c.

Lei Complementar n. 123, de 14 de dezembro de 2006. Disponível em $<$ www.receita.fazenda.gov.br/Legislacao/LeisComplementares/2006>. Acesso em: out. 2006d.

CARVALHO, C. E. Reformas tributárias recentes na Argentina, Chile e México: uma visão geral. In: MEYER, A. (Org.). Finanças públicas: ensaios selecionados. Brasília: IPEA/FUNDAP, 1997, p. 305-365.

O governo Lula, triunfo espetacular do neoliberalismo, Margem Esquerda, São Paulo, n. 3, p. 131-146, 2004.

GORI MAIA, A.; QUADROS, W.J. de; SIQUEIRA DE OLIVEIRA, H. Retroceso social en las regiones metropolitanas de São Paulo - Brasil. Texto apresentado nas $X$ Jornadas de Economia Crítica, ¿Alternativas al capitalismo? Barcelona, 23 a 25 de marzo de 2006, 24p.

LUGONES, C. G. F. O Imposto sobre Propriedade Territorial Rural: algumas considerações à luz da Emenda Constitucional 42/2003. In: ROSA, E. (Dir.). A reforma tributaria da Emenda Constitucional n. 42/2003. Aspectos polêmicos e controvertidos. Rio de Janeiro: Editora Lumen Juris, 2004, p.1-26.

MAHON, J. E. Causes of Tax Reform in Latin America, 1977-95. Latin America Research Review, University of Texas Press, v. 39, n. 1, p. 3-30, Feb. 2004.

OCDE - Organização para Cooperação e Desenvolvimento Econômico. Etudes économiques de l'OCDE: Brésil. Paris: OCDE, 2001.

OECD - Org. Economic Coop. and Development. OECD Tax Database, Paris: OECD, 24 juil. 2006.

PALOCCI FILHO, A.; DIRCEU, J. Exposição de Motivos, E.M.I. n. 84/MF/Casa Civil. Brasília: Casa Civil, 30 abr. 2003.

POCHMANN, M.; CAMPOS, A.; AMORIM, R.; SILVA, R. (Org.). Atlas da exclusão social: os ricos no Brasil. São Paulo: Cortez, v. 3, 2004.
PRESIDÊNCIA DA REPÚBLICA. Proposta de Reforma Tributária do Governo: O que é, como é e para que é. Presidência da República, Brasília, 1996. Disponível em <www. planalto.gov.br/publi_04/COLECAO/PROTRI.HTM>. Acesso em: out. 2006.

PRZEWORSKI, A. Democracy and the Market: Political and Economic Reform in Eastern Europe and Latin America. Cambridge: Cambridge University Press, 1991.

RAWLS, J. A Theory of Justice. Cambridge-Mass: Harvard University Press, 1971.

Justiça como eqüidade: uma reformulação. São Paulo: Martins Fontes, 2003.

REZENDE, F.; CUNHA, A. (Org.). Contribuintes $e$ cidadãos: compreendendo o orçamento federal. Rio de Janeiro: Editora FGV, 2002.

UNAFISCO SINDICAL. 10 anos de derrama: a distribuição tributária no Brasil. Brasília: Unafisco Sindical, Sindicato Nacional dos Auditores-Fiscais da Receita Federal, nov. 2006. 204p.

UNITED NATIONS Development Program, Human Development Report 2006, New York: Palgrave Macmillan, 2006. 440p.

WILLIAMSON, J. The Progress of Policy Reform in Latin America. In: (Ed.). Latin American Adjustment: How Much Has Happened? Washington: IIE, 1990a.

What Washington Means by Policy Reform. In:_. (Ed.). Latin America Adjustment: How Much Has Happened ? Washington: IIE, 1990b

WORLD BANK. World Development Report 1989. Oxford University Press, 1 juil. 1989.

WORLDBANK. Lessons of Tax Reform. Washington DC, 1992.

\section{Notas}

1 A autora e o autor agradecem as críticas e sugestões de pareceristas anônimos da Revista Katálysis.

2 Vera respeito Afonso e Meirelles (2006, p. 9-13).

\section{Alexandrine Brami-Celentano}

Doutoranda no Institut d'Etudes Politiques de Paris (Sciences Po)

Pesquisadora no Centre d'Etudes et de Recherches Internationales (CERI)

http://www.ceri-sciences-po.org/index.php 


\section{Carlos Eduardo Carvalho}

Doutor em Ciências Econômicas pelo Instituto de Economia da Universidade Estadual de Campinas (UNICAMP)

Professor do Programa de Pós-Graduação em Economia e do Departamento de Economia da Pontifícia Universidade Católica de São Paulo (PUCSP) Campus Monte Alegre

Edifício Reitor Bandeira de Mello

Rua Ministro de Godói, 969, $4^{\circ}$ andar, sala 4E17 Perdizes

São Paulo - SP

CEP: 05015-901 